\section{Clinical outcome following cataract surgery in very elderly patients}

PP Syam, H Eleftheriadis, AG Casswell,

GP Brittain, BK McLeod and CSC Liu

\begin{abstract}
Purpose The number of very elderly patients waiting for cataract surgery is predicted to increase. The aim of our study was to determine the clinical outcome following cataract surgery in this age group.

Methods In this retrospective study, patients aged 96 years and above, who underwent cataract surgery between June 1993 and January 2001, were identified. Clinical data were retrieved from their medical records. Living patients were further invited for clinical examination. Results In all, 34 eyes of 21 patients (20 females) were identified. Six patients were deceased. In total, 30/34 eyes had phacoemulsification and four had extracapsular extraction. Preoperative vision was $\leq 6 / 36$ in $24 / 34$ eyes $(70.59 \%)$ and
\end{abstract} $\leq \mathrm{CF}$ in $16 / 34$ eyes $(47.06 \%)$. Postoperative vision was $\geq 6 / 60$ in $25 / 34$ eyes $(73.53 \%$ ), $\geq 6 / 18$ in $21 / 34$ eyes $(61.76 \%$ ), and $\geq 6 / 9$ in $10 / 34$ eyes $(29.41 \%)$. Visual acuity improved in $24 / 34$ eyes $(70.59 \%)$ and remained the same in 6/34 eyes. Complications included anterior capsule tear (three), zonular dialysis with vitreous loss (one), posterior capsule rupture with vitreous loss (one), incarceration of iris to paracentesis wound (two), postoperative uveitis (two), and posterior capsular opacification (19). In all, 7/34 eyes had undergone YAG capsulotomy.

Conclusion Surgeons should not be deterred from offering cataract surgery to the very elderly as successful visual rehabilitation is the norm. A further prospective multicentre study is required to confirm the benefits and assess the risks of cataract surgery in this age group.

Eye (2004) 18, 59-62. doi:10.1038/sj.eye.6700521

Keywords: outcome; cataract surgery; centenarians; very elderly patients

\section{Introduction}

For many surgical procedures, the risk of complications is positively correlated to age, while the outcome is negatively correlated to age. Some ophthalmologists probably feel that this also applies to cataract surgery. ${ }^{1}$ In this paper, although the authors did not suggest advanced age (90 years and more) as a contraindication, they suggested that the benefits of cataract surgery were reduced because of high frequency of macular degeneration, reduced adaptation to aphakic lenses, and high frequency of pre- and postoperative complications. With rapidly ageing populations and greater life expectancy, the number of very elderly patients undergoing cataract surgery will inevitably increase. ${ }^{2}$

Cataract surgery in very elderly patients is challenging, as the majority of these patients have very dense nuclear cataract. As age advances there is gradual reduction in corneal endothelial cell density, and a zonule-free zone on the anterior capsule, ${ }^{3}$ thus possibly predisposing to higher complication rates. In addition to these, cataract surgery in very elderly patients could be fraught with difficulties, as they may not be able to lie flat because of neck or back problems.

Uncooperative patients, and those who are hard of hearing could make matters worse. Preexisting ocular and general comorbidity and short life expectancy may deter some ophthalmologists from performing cataract surgery in very elderly patients.

However, there have been a number of previous studies on cataract surgery in elderly patients. ${ }^{4-7}$ The study carried out by Lundstorm et $\mathrm{al}^{4}$ has shown improvement in visual acuity in $84.3 \%$ of patients above 85 years of age.

Similarly, a study carried out by Applegate et $a l^{5}$ has shown improved visual acuity in a majority of the patients (88\%) above 70 years following cataract surgery. However, according to Westcott et al, ${ }^{6}$ in patients older than 80 years,
Sussex Eye Hospital Brighton, UK

Correspondence:

CSC Liu

Sussex Eye Hospital, Eastern Road Brighton BN2 5BF, UK Tel.: + 441273606126 Fax: + 441273693674 E-mail: CSCLiu@aol.com

Received: 4 October 2002 Accepted in revised form: 24 January 2003

This material was presented as a poster at ARVO, Fort Lauderdale, May 2002 and the Royal College of Ophthalmologists meeting Manchester, May 2002 
the likelihood of achieving an acuity of $6 / 12$ or better postoperatively is reduced by a factor of 4.6 compared to patients aged 60-69 years.

With a rapidly ageing population, ophthalmologists will be faced with the challenge of performing more and more cataract surgery in very elderly patients. In spite of the above worries, there has been no previous study on cataract surgery in very elderly patients (96 years and above). We therefore carried out this retrospective study in our unit in order to find out the clinical outcome following cataract surgery in this age group. We have chosen 96 years or above as there would be very few patients if we were to choose 100 years or above.

\section{Materials and methods}

In this retrospective study, patients aged 96 years and above, who underwent cataract surgery at Sussex Eye Hospital, Brighton, UK, between June 1993 and January 2001, were identified from operating theatre records.

Retrospective data collected from case notes in all patients were analysed. These included preoperative and operative details, intraoperative and postoperative complications. Living patients were then invited for clinical examination. During the review, best-corrected Snellen visual acuity, corneal status, IOL position, changes in anterior and posterior capsule, and posterior segment pathology were noted.

\section{Results}

Of 21 operated patients (34 eyes), 15 living patients (26 eyes) were reviewed after a mean follow-up of 28.22 months (range 3-63 months) following cataract surgery (Table 1). Six patients were deceased and the final assessment was carried out after a mean follow-up period of 3 weeks (range 2-12 weeks). In these patients, the time interval between cataract surgery and death varied from 6 months to 5 years. Cardiac arrest was the commonest cause of death.

Preoperative vision was $\leq 6 / 36$ in $24 / 34$ eyes $(71 \%)$ and $\leq \mathrm{CF}$ in $16 / 34$ eyes (47\%). Out of 21 patients, the oldest patient was 105 years old. All except one were female. In all, 30 eyes had undergone phacoemulsification and the remaining four eyes

Table 1 Follow-up period in quartiles

\begin{tabular}{lc}
\hline Follow-up duration (months) & No. of cases \\
\hline $3-15$ & 6 \\
$16-30$ & 7 \\
$31-45$ & 9 \\
$46-63$ & 4 \\
\hline
\end{tabular}

Table 2 Details of cataract surgery in our study

\begin{tabular}{lc}
\hline Phacoemulsification & 30 cases \\
Planned ECCE & 4 cases \\
PMMA lens implanted (Rayner 552A) & 24 \\
Foldable acrylic lens (Alcon MA60BM) & 8 \\
Silicone implant & 2 \\
Local anaesthesia & 19 patients \\
General anaesthesia & 2 patients \\
\hline
\end{tabular}

planned extracapsular extraction. Phacoemulsification was carried out through a scleral tunnel in 28 eyes and the remaining two through superior clear corneal incision. A PMMA intraocular lens (Rayner 552A) was implanted in 24 eyes, a foldable acrylic implant (Alcon MA60BM) in eight eyes, and a silicone implant in two eyes. The majority of these patients (19 cases) were operated under local anaesthesia (Table 2).

Postoperative vision was $\geq 6 / 60$ in $25 / 34$ eyes (74\%), $\geq 6 / 18$ in $21 / 34$ eyes $(62 \%)$, and $\geq 6 / 9$ in $10 / 34$ eyes (29\%). Postoperative best-corrected Snellen visual acuity improved (mean 2.5 lines, range 1-6 lines) in 24/34 eyes $(71 \%)$ and remained the same in $6 / 34(18 \%)$ eyes (Figure 1). Postoperative vision deteriorated in four eyes (11\%) because of the underlying severe ARMD. In total, 21 eyes had ARMD of varying degree, of which four eyes had advanced ARMD.

Posterior capsular thickening was the commonest complication, seen in 19/34 eyes, and all these patients were implanted with a PMMA implant (Rayner 552A). Eight eyes had undergone YAG capsulotomy. Other complications were anterior capsule tear (three), zonular dialysis with vitreous loss (one), posterior capsule rupture with vitreous loss (one), incarceration of iris to paracentesis wound (two), postoperative uveitis (two), and anterior capsular fibrosis (six) (Table 3).

\section{Discussion}

Most of the patients treated by ophthalmologists are at the extremes of life - childhood or old age. Recent demographic changes have led to fewer children and more elderly patients needing ophthalmic consultation. ${ }^{8}$ Low vision is considered to be a significant and often unnoticed handicap in the very elderly. ${ }^{9-11}$ It appears that impaired vision in the very elderly is an important risk factor for imbalance, perhaps leading to falls and injury. ${ }^{12-14}$ Accidents are the sixth leading cause of death in those over the age of 65 years; half of these deaths are related to fall. Moreover, hip fracture in the elderly is commonly caused by fall. ${ }^{14}$

Cataract is the most prevalent eye disease in the elderly in the world and is a leading cause of visual loss in the developing and developed world. ${ }^{15-18}$ With greater 


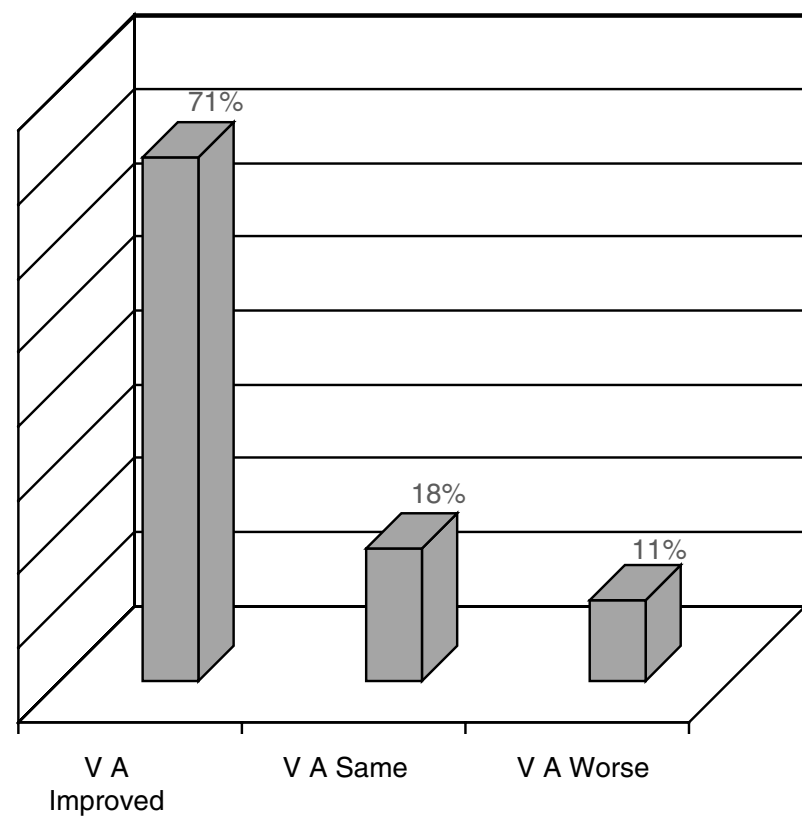

Figure 1 Bar chart showing change in postoperative visual acuity following cataract surgery in very elderly patients in our study.

Table 3 Complications following cataract surgery in very elderly patients in our study

\begin{tabular}{lc}
\hline Type of complication & No. of cases \\
\hline Posterior capsular thickening & 19 \\
Anterior capsular fibrosis & 6 \\
Anterior capsular tear & 3 \\
Zonular dialysis with vitreous loss & 1 \\
Posterior capsular rupture with vitreous loss & 1 \\
Postoperative uveitis & 2 \\
Incarceration of iris to paracentesis wound & 2 \\
\hline
\end{tabular}

life expectancies and increasing demand for improved quality of life, the number of very elderly patients undergoing cataract surgery is expected to grow substantially. ${ }^{19}$ Even in patients with macular degeneration, where central vision is lost, the peripheral visual field necessary for confident navigation can be improved by cataract surgery. Our study showed that postoperative visual acuity improved in 24/34 cases $(71 \%)$ and deteriorated in $11 \%$ of the cases, which was attributed to the underlying advanced ARMD (Figure 2).

Posterior capsule thickening was the commonest complication (19/34 eyes-56\%) seen in our study. Interestingly, all these cases were implanted with PMMA implant (Rayner 552A). As the PCO rate is high with the PMMA implant and very elderly patients have associated general comorbidity limiting their mobility, it may favour the argument towards using a foldable

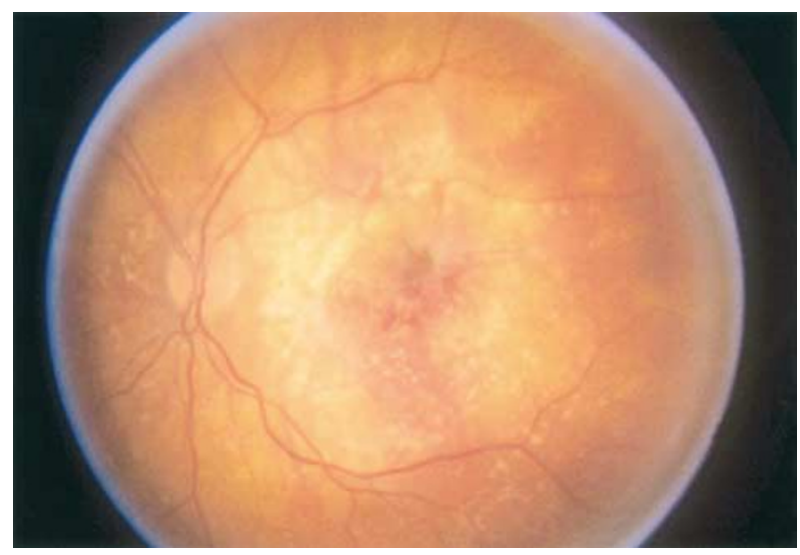

Figure 2 Fundus photograph showing advanced age-related macular degeneration in one of the very elderly patients who was satisfied with cataract surgery.

acrylic implant in this age group. Vitreous loss was seen in $2 / 34(5.8 \%)$, and both settled nicely following anterior vitrectomy. Other complications were negligible.

Contrary to common belief, complications following cataract surgery were low in our study. As deterioration of vision was associated with advanced ARMD following cataract surgery in our study and previous studies did not show any benefit following cataract surgery in patients with advanced ARMD ${ }^{20}$ cataract surgery should be withheld in these patients until cataracts become advanced.

One of the main concerns regarding cataract surgery in the very elderly is the short life span. A study on surgical procedures in centenarians (100 years of age and older) carried out by Cogbill et $a l^{21}$ has shown $100 \%$ 1-year survival rate after cataract surgery. In our study, six patients died following cataract surgery with no direct link to the surgery or anaesthesia used. The interval between surgery and death varied between 6 months and 5 years in the six who had died. Cardiac arrest was the commonest cause of death ( $3 / 6$ patients) in our series. As the majority of cataract surgery is now carried out under modern safe local anaesthesia, the mortality following cataract surgery in very elderly patients is negligible. As the number of cases is small in our study, we did not carry out any statistical analysis.

Although our study was retrospective and involved only 21 patients (34 eyes), it has shown that cataract surgery is safe in very elderly patients with improvement in vision in the majority of patients. Our study also showed acceptable rates of complications following cataract surgery compared to the UK national average. ${ }^{22}$ Further prospective multicentre studies may confirm the benefits and acceptable risks of cataract surgery in this age group. 


\section{Acknowledgements}

No proprietary interest or research funding.

\section{References}

1 Bernth-Petersen P, Ehlers N. Cataract extraction in the nineties. Acta Ophthalmol 1983; 61: 392-396.

2 Wong TY. Cataract surgery in patients with cataract and age related macular degeneration: do the benefits outweigh the risks? Br J Ophthalmol 2000; 84: 1337-1341.

3 Sakabe I, Oshika T, Lim SJ, Apple DJ. Anterior shift of zonular insertion onto anterior surface of human crystalline lens with age. Ophthalmology 1998; 105: 295-299.

4 Lundstorm M, Stenevi U, Thorburn W. Cataract surgery in very elderly patients. J Cataract Refract Surg 2000; 26: 408-414.

5 Applegate WB, Miller ST, Elam JT, Freeman JM, Wood TO, Gettlefinger TC. Impact of cataract surgery with lens implantation on vision and physical function in elderly patients. JAMA 1987; 257: 1064-1066.

6 Westcott MC, Tuft SJ, Minassian DC. Effect of age on visual outcome following cataract extraction. Br J Ophthalmol 2000; 84: 1380-1382.

7 Elam JT, Graney MJ, Applegate WB, Miller ST, Freeman JM, Wood TO et al. Functional outcome one year following cataract surgery in elderly persons. J Gerontol 1988; 43: 122-126.

8 Goldcare MJ, Ingram RM. Changing workload in ophthalmology: some observations from routine statistics. BMJ 1983; 286: 1560-1563.

9 Hitchings RA. Visual disability and the elderly. BMJ 1989; 298: 1126-1127.

10 Elliott AJ. Poor vision and the elderly-A domiciliary study. Eye 1989; 3: 365-369.
11 Branch LG, Horowitz A, Carr C. The implications for everyday life of incident self-reported visual decline among people over age 65 living in community. Gerontologist 1989; 29: 359-365.

12 Stones MJ, Kozma A. Balance and age in the sighted and blind. Arch Phys Med Rehabil 1987; 68: 85-89.

13 Gerson LW, Jarjoura D, McCord G. Risk of imbalance in elderly people with impaired hearing or vision. Age Ageing 1989; 18: 31-34.

14 Tinetti ME, Williams TF, Mayewski R. Fall risk for elderly patients based on number of chronic disabilities. Am J Med 1986; 80: 429-434.

15 Pizzarello LD. The dimensions of the problem of eye disease among the elderly. Ophthalmology 1987; 94: 1191-1195.

16 Whitemore WG. Eye diseases in a geriatric nursing home population. Ophthalmology 1988; 96: 393-398.

17 Lim ASM, Khoo CY, Ang BC, Tan J, Heng LK. Eye diseases in the elderly in Singapore. Ann Acad Med 1987; 16: 46-53.

18 Gibson JM, Rosenthal AR, Lavery J. A study of the prevalence of the eye disease in the elderly in an English community. Trans Ophthalmol Soc UK 1985; 104: 196-203.

19 Jay JL, Devlin ML. The increasing frequency of surgery for cataract. Eye 1990; 4: 127-131.

20 Armbrecht AM, Findlay C, Kaushal S, Aspinall P, Hill AR, Dhillon B. Is cataract surgery justified in patients with age related macular degeneration? A visual function and quality assessment. Br J Ophthalmol 2000; 84: 1343-1348.

21 Cogbill TH, Strutt PJ, Landercasper J, Crosse L. Surgical procedures in centenarians. Wisconsin Med J 1992; 91: 527-529.

22 Desai P, Minassian DC, Reidy A. National cataract surgery survey 1997-98: a report of the results of the clinical outcomes. Br J Ophthalmol 1999; 83: 1336-1340. 